\title{
NAILFOLD CAPILLAROSCOPY AND MICROVASCULAR INVOLVEMENT IN DIABETES MELLITUS
}

Camila Ferreira Lima (Hospital Universitário Evangélico Mackenzie, Curitiba, PR, Brasil), Igor Henrique Morais (Hospital Universitário Evangélico Mackenzie, Curitiba, PR, Brasil), Kelvin Suckow (Hospital Universitário Evangélico Mackenzie, Curitiba, PR, Brasil), Deborah Colombo (Rheumatology Unit Hospital Universitário Evangélico Mackenzie, Curitiba, PR, Brasil), Thiago Alberto Fernandes Gomes dos Santos (Rheumatology Unit - Hospital Universitário Evangélico Mackenzie, Curitiba, PR, Brasil), Thelma Laroca Skare (Rheumatology Unit - Hospital Universitário Evangélico Mackenzie, Curitiba, PR, Brasil)

\section{BACKGROUND}

Microvascular lesions are the hallmark of Diabetes Mellitus (DM), contributing to the patient's morbidity and mortality. Eye and kidney damage are well known complications that mirror this kind of involvement . Flow disturbances in skin microcirculation may precede development of typical diabetic complications. Nailfold capillaroscopy (NC) is widely used to study vascular lesions in rheumatic diseases such as scleroderma and dermatomyositi. Due to its low cost and being easy to execute, the use of this instrument in other clinical situations has been suggested. Kuryliszyn-Moskal et al. demonstrated that NC reflect the alterations of microcirculation seen in DM; others proposed its use following the progression of diabetes complications.

\section{MATERIALS AND METHODS}

Cross-sectional study including 140 individuals (70 with DM and 70 controls). To be included patients should be older than 18 years of age and have DM diagnosed according to the American Diabetes Association criteria. Epidemiological and clinical variables were collected from patient's charts. Fundus ophthalmoscopy, NC, analysis of microalbuminuria and renal clearance as well as fasting glycaemia and $\mathrm{HbA1c}$ values were studied simultaneously.

\section{RESULTS}

Capillary density was reduced and vascular dilatation was increased in DM patients when compared to controls (both with $p<0.0001$ ). In DM individuals the number of dermal papillary capillaries $/ \mathrm{mm} 3$ correlated with microalbuminuria ( $p=0.02)$, patient's age $(p=0.03)$, values of HbA1c $(p=0.03)$. Patients with diabetic retinopathy and using antiplatelet agents had lower capillary density $(p<0.0001$ and 0.04 respectively). Capillary dilatation was associated with disease duration $(p=0.04)$.

\section{CONCLUSION}

DM microvascular disease DM is reflected in NC 